\section{O cuidado como trabalho: entre desafios e avanços}

\section{Care as work: challenges and advances}

BORGEAUD-GARCIANDÍA, Natacha. (org.) (2018), El trabajo de cuidado, Buenos Aires, Fundación Medifé Edita.

\section{Silvana Maria Bitencourt ${ }_{(1)}$}

(D) https://orcid.org/0000-0002-3183-373X

\section{Cristiane Batista Andrade (2)}

(D) https://orcid.org/0000-0003-1441-9171

(1) Professora Associada da Universidade Federal de Mato Grosso (UFMT), Cuiabá, MT, Brasil. E-mail: silvanasocipufmt@gmail.com

(2) Pesquisadora da Fundação Oswaldo Cruz (FIOCRUZ/RJ), Rio de Janeiro, RJ, Brasil. E-mail: cristiane.andrade@fiocruz.br

DOI: $10.1590 / 3510415 / 20$

A obra, organizada por Natacha BorgeaudGarciandía (2018), garante aos leitores/as um apanhado significativo de temáticas correspondentes ao trabalho de cuidado, destacando-se os estudos empíricos na América Latina, além das reflexões que contribuem para a complexidade do tema. É importante salientarmos que, apesar das críticas direcionadas ao essencialismo da obra In a different voice, de Carol Gilligan (1982), a mesma é referenciada neste campo de estudos por inaugurar uma nova fase no debate sobre cuidado, pois é a partir de seus trabalhos empíricos, que a presença de uma "voz diferente" possibilita questionar os modelos abstratos e princípios imparciais de justiça. Gullian concebe ética do cuidado, como um modelo alternativo para as concepçôes de moral clássicas. Outra autora que também recebe destaque neste campo de estudos é Joan Tronto, que, ao desvincular ética de cuidado, conforme Gilligan, desenvolve uma discussão que evidencia a desvalorização do trabalho de cuidado, o qual resultaria de uma divisão do trabalho moral.
A coletânea organizada em nove capítulos versa sobre pesquisas contemporâneas referentes ao cuidado, a partir de um sofisticado corpo empírico de artigos movidos pela reflexão sobre o que é cuidar e quem cuida, além das dimensôes do cuidado, que implicam nas relações sociais. Na primeira pesquisa, há quatro capítulos. O primeiro deles, de Maria José Magliano, intitulado "Mujeres Migrantes y empleo doméstico en Córdoba: luchas y resistencias frente a formas de explotación y violencia laboral", analisa as formas de resistências e de mobilização de empregadas domésticas peruanas, que trabalham em Córdoba/AR. O trabalho doméstico é problematizado como uma atividade temporária, feita pelas mulheres migrantes peruanas, a fim de contribuir para um projeto familiar migratório. Contudo, os achados demonstram que essas mulheres tendem a permanecer neste tipo de emprego, podendo vivenciar problemas como informalidade, precarização e discriminação, que operam nas interseccionalidades de gênero. $\mathrm{O}$ texto mostra como as fortes naturalizaçóes de gênero, vinculadas ao trabalho doméstico, contribuem para que esse tipo de trabalho não seja reconhecido por meio de conhecimentos necessários, possuídos pela trabalhadora para realizá-lo. Neste sentido, o texto aponta que as empregadas domésticas sentem a necessidade de articulação coletiva - tanto por serem domésticas, como por serem migrantes - para que o debate seja efetivado no âmbito das instituições, a fim de que elas sejam tratadas como trabalhadoras formais e, consequentemente, com direitos trabalhistas.

O texto "Los itinerarios de cuidadores remunerados en el Gran Buenos Aires", de Liliana Findling, Maria Lehner e Estefania Cirino, problematiza o envelhecimento populacional e as estratégias que as sociedades têm adotado para cuidar de idosos com alto grau de dependência, analisando que o trabalho de cuidado dentro das famílias tem sido historicamente delegado, em grande parte, às mulheres - filhas e esposas. Contudo, com a entrada massiva delas no mercado de trabalho, as famílias começaram a comprar o trabalho de cuidado de um cuidador formal, que, na grande maioria dos casos, continua sendo uma mulher. As autoras apontam que, para cuidar, é necessário que quem cuida também seja cuidado, atentando-se, assim, para o trabalho que as próprias 
cuidadoras desempenham, e que compreende tanto a dimensão prática, quanto a afetiva, exigindo de seus corpos grande esforço físico e emocional.

Segundo as autoras, nos últimos anos, os órgãos do Estado têm formado cuidadoras domiciliares em instituiçóes educativas e sanitárias, além de organizações da sociedade civil. Neste sentido, elas questionam se, nas trajetórias das cuidadoras para o atendimento de idosos/as, seus serviços apresentavam uma qualidade diferenciada, comparando as que receberam formação ou não, como também seu próprio entendimento sobre o que é saúde, para além da perspectiva biologicista.

As autoras destacam, ainda, as modalidades de emprego e as trajetórias laborais das cuidadoras e abordam as qualidades necessárias para a atividade, sem deixarem de considerar a questáo do autocuidado. A pesquisa constatou a inserção das entrevistadas em clínicas privadas e geriátricas, nas quais, após adquirirem experiência, elas optam por se tornarem “empresárias de si mesmas”. Há, porém, contradições nisso, pois, quando indagadas sobre os motivos dessa opção, embora elas enfatizem a importância da questão salarial, afirmam que estão na profissão por uma questão de vocação, havendo, portanto, uma romantização da atividade de cuidado.

Sobre a formação para o cargo, as entrevistadas comentam que a mesma contribuiu muito para seu desejo de fazerem o curso de enfermagem. Apesar de se sentirem seguras por disporem dessa formação, dizem que só com a experiência é que aprendem a cuidar. Em relação ao autocuidado, muitas vivenciam problemas de saúde e associam suas doenças às atividades de trabalho: doenças musculares e estresse; dormir pouco, ter alimentação desregrada, não fazer exercícios físicos, automedicar-se e tomar suplementos alimentícios. Nesse contexto, "cuidar do outro" pode significar deixar de cuidar de si. A fim de confrontar esse paradoxo, as autoras sugerem uma política integral de cuidado para idosos e cuidadoras remuneradas, com a finalidade de diminuir as desigualdades sociais e de gênero.

Por sua vez, o texto de Natacha BorgeaudGarciandía, "Intimidad, sexualidad, demencias: Estrategias afectivas y apropriación del trabajo de cuidado en contextos desestabilizantes", analisa, no contexto argentino, o trabalho de cuidado em residências de idosos/as com alto grau de dependência e investiga a possibilidade de conflito entre cuidadoras. A autora realizou entrevistas com cuidadoras provenientes da Argentina, Paraguai e Peru, mas focalizou essencialmente as peruanas. Ela explicita que as paraguaias e as peruanas chegam à Argentina em busca de uma situação de vida melhor, e ingressam majoritariamente em trabalhos domésticos e de cuidado. O texto expóe que o trabalho de cuidado destinado a lidar com corpos que apresentam demência senil escancara a ideia de finitude corporal e animalidade presentes na condição humana; assim, fenômenos como as doenças crônicas degenerativas e a morte são analisados, reafirmando como é fundamental o trabalho de cuidado para lidar com corpos nestas condições de dependência total. $\mathrm{O}$ texto também apresenta os desafios diante da complexidade de corpos que se comunicam de maneira diferenciada, levando as cuidadoras a criarem, por meio da prática, estratégias para lidar com outras formas de linguagem no cuidado de idosos com demência senil.

O texto de Helena Hirata, intitulado "Subjetividad y sexualidad en el trabajo de cuidado", destaca a emergência dos temas da sexualidade, da subjetividade e das emoçóes, partindo de uma investigação realizada em três países: Brasil, França e Japão. Hirata apresenta a centralidade da sexualidade e da subjetividade, no trabalho de cuidado, a fim de pensar a formação dos/ as cuidadores/as, além das táticas que eles/as tendem a adotar para se manter no emprego. A autora destaca os estudos de referência sobre sexualidade e emoçôes no trabalho de cuidado e problematiza os conflitos que este tipo de trabalho pode gerar na identidade dos/as trabalhadores/as do cuidado, de maioria feminina. Assim, para a autora, os aspectos prático e teórico do trabalho de cuidado envolvem sofrimento, racismo, doenças, morte e uma qualificação pouco discutida entre os/as trabalhadores/as, devendo-se considerar e analisar a sua dimensão emocional e subjetiva.

Nesta primeira seção do livro apresentada, os estudos apontam que são as mulheres que ainda realizam este tipo de trabalho, com uma série de significados permeando poderes e saberes no cuidado (Andrade, 2015). Nos últimos anos, eles também referem que as análises assumem uma perspectiva interdisciplinar, que dialoga diretamente com os 
estudos de gênero e feministas, politizando o debate acadêmico, especialmente dando visibilidade às emoçóes e à sexualidade, aspectos que não podem ser ignorados neste tipo de trabalho que envolve o corpo de quem cuida e de quem é cuidado (Soares, 2012).

Em sua segunda seção, o livro apresenta três capítulos. O primeiro deles, intitulado "Mujeres migrantes y la gestión de los cuidados. La enfermería en el horizonte laboral", de Ana Barral, póe em debate a questão de imigrantes na Argentina, que trabalham em enfermagem, ou aspiram ao exercício dessa atividade. É por meio das análises da complexidade do cuidado (reprodução da vida, assalariamento, trabalho doméstico não remunerado e força de trabalho desempenhada especialmente por mulheres), que a autora coloca em debate a importância do processo migratório no trabalho de enfermagem. As entrevistas em profundidade, realizadas com docentes, enfermeiras/ as e estudantes estrangeiras, descrevem os fluxos migratórios de paraguaias, bolivianas e peruanas na enfermagem argentina, e apontam o trabalho de cuidado como uma possibilidade de acesso ao trabalho formal e aos direitos trabalhistas, bem como de reconhecimento social em contraposição ao "peso de ser imigrante" (p. 130). A discussão sobre as exigências da profissionalização da categoria das cuidadoras na Argentina, assim como ocorreu no Brasil, expressa as contradições entre a (des)valoração social, as possibilidades de mobilidade ascendente e as representaçôes de exercício da atividade pela "vocação". Um dos aspectos interessantes deste capítulo é o fato de a autora considerar as particularidades dessa profissão e suas relaçóes com o processo migratório, o que traz avanços na discussão sobre a invisibilidade do uso da mão de obra de migrantes em uma sociedade que vive e precisa do trabalho de cuidado.

O capítulo de autoria de Silva Balzano, "Cuidado y identidad en el que hacer enfermero en la Colonia Montes de Oca", analisa o trabalho de enfermeiras argentinas na área de cuidado em saúde mental, sob a perspectiva das identidades profissionais e suas construçóes sociais quanto à disciplina no trabalho e à imagética da docilidade, da subserviência e da religiosidade. A autora desenvolve sua pesquisa por meio de entrevistas que possibilitam reconhecermos quais são as dificuldades e contradições relativas ao cuidado de pessoas com doenças psiquiátricas: lidar com o sujo, com a nudez de alguns pacientes, com os surtos psicóticos, com os estigmas vividos pelos/ as pacientes, a despeito da doença psiquiátrica. Ao mesmo tempo, as entrevistadas desprendem carinho e afeto como uma atividade terapêutica do cuidado. Os depoimentos das enfermeiras corroboram a ideia de que há um auxílio e uma prontidão da enfermagem, em ajudar as outras profissóes no cuidado aos pacientes de psiquiatria.

O terceiro capítulo da segunda seção, "La profesión enfermera y el trabajo de cuidado", de Wlosko e Ros, tem como finalidade analisar o trabalho de cuidado de enfermeiras, sob a ótica da psicodinâmica do trabalho e as teorias do "care". As autoras discutem a diminuição do número de pessoas na enfermagem, em decorrência da flexibilização e precarização do trabalho, da sobrecarga das atividades, da desvalorização profissional e das violências sofridas no cotidiano laboral. Além disso, elas destacam as relações de poder entre os grupos profissionais e, portanto, o pouco reconhecimento entre os pares, ao mesmo tempo em que ocorre a valorização social das enfermeiras pelas pessoas que recebem o cuidado. A pesquisa avança na compreensão das construçóes das estratégias coletivas de defesa e que são, portanto, diferenciadas de acordo com o gênero. Apoiadas em Molinier, as autoras salientam que tais estratégias, construídas coletivamente para lidar com os sofrimentos no trabalho, estão relacionadas com as construçóes sociais sobre ser enfermeira, em que o sofrer com o outro e ter empatia pelos pacientes são meios para permanecer no trabalho e lidar com os sofrimentos. Assim, os achados de Wlosko e Ros oferecem subsídios para entender as maneiras como a enfermagem se ocupa do sofrimento do outro e, também, os desafios da própria categoria profissional diante das condições de trabalho adversas, contribuindo para as reflexões sobre os modos de ressignificar e enfrentar as atribuições prescritas pela organização do trabalho.

Os três capítulos desta seção corroboram a ideia da complexidade do trabalho de cuidado e suas interfaces com as relaçóes sociais, tal como aponta Kergoat (2016). Chamamos atenção para o fato de que a complexidade do trabalho de cuidado pode estar atrelada aos fluxos migratórios, tal como apontado na 
pesquisa realizada por Barral. Ainda que essa autora não tenha aprofundado a questão das discriminaçóes e das possíveis violências laborais, pelo fato de as entrevistadas serem imigrantes, este enfoque merece ser verificado em futuras pesquisas. A importância dos fluxos migratórios na profissão de enfermagem já vem sendo problematizada, haja vista um estudo sobre a relação entre a imigração e o trabalho de enfermagem na América do Sul, entre 2011 e 2016, que aponta que os motivos da imigração estão relacionados com o desejo de melhoria das condiçôes de vida e de salário, independência econômica e estabilidade laboral. Por sua vez, os obstáculos encontrados no país de destino dizem respeito às dificuldades econômicas iniciais e às discriminaçóes enfrentadas pelas entrevistadas por serem estrangeiras, embora elas consigam, ao longo do tempo, respeito e reconhecimento de suas atividades (Paho, 2011).

Por outro lado, o conjunto dos textos nos faz refletir sobre os saberes necessários para o cuidado na esfera produtiva e suas imbricaçóes, a partir da síntese apresentada por Barral: "La tensión entre saberes 'naturales y professionales" (p. 124). Ou seja, as formas como as cuidadoras constroem os saberes para lidar com os desafios do cuidado profissional e as relaçóes de poder entre grupos profissionais distintos (Andrade, 2015), na área de saúde, parecem ser centrais para desvendar as formas pelas quais as enfermeiras lidam com as hierarquias da profissão, com as relaçôes com a medicina e com as técnicas/ auxiliares de enfermagem, que nem sempre possuem o diploma de ensino superior.

Além disso, o conjunto de textos contribui para evidenciar as escassas discussões sobre a presença de homens no trabalho do cuidado e como eles constroem suas carreiras no cuidado em saúde (Kluczyńska, 2017). Por isso, ressaltamos a importância de os estudos serem mais aprofundados, com a intenção de se descobrir as diferenciações entre ser homem e mulher em uma profissão predominantemente feminina.

Na última seção, o capítulo de Pascale Molinier, "El cuidado puesto a prueba por el trabajo: vulnerabilidades cruzadas y saber-hacer discreto", entende, por meio da psicodinâmica, o trabalho de cuidado como aquele que envolve aspectos emocionais, subjetivos e aprendizagens, técnicas ou não, de quem cuida.
Há construção de saberes e fazeres para lidar com os constrangimentos, antecipar atividades, dissimular emoçóes e esforços, proporcionar conforto e escuta às pessoas cuidadas, dentre outros aspectos, além do fato de que o trabalho de cuidado é, por vezes, invisível e permeia um saber-fazer discreto. Diante disso, a autora apresenta as estratégias construídas pelas cuidadoras em face das dificuldades no trabalho de cuidado, aprofundando a questão da complexidade do cuidar, como uma atividade em que as construçóes sociais e históricas de ser mulher e cuidadora influenciam nos saberes e fazeres, na ética e nos desafios de cuidar do outro, em situação de vulnerabilidade ou não.

O capítulo de Patrícia Paperman, "La ética del cuidado y las voces diferentes de la investigación", traz a discussão pautada em Gilligan, que critica diretamente o modelo universalista de justiça e moral, que excluiu as "vozes diferentes" que não ouvimos e que, historicamente, teriam muito a falar sobre o cuidado, especialmente as mulheres cuidadoras. A autora também traz a crítica feminista de Joan Tronto, que irá politizar o trabalho de cuidado. Saindo do plano individual, Paperman sugere a necessidade de conceituar o que é cuidado, buscando maior aprofundamento sobre os saberes que possuem suas protagonistas, que foram excluídas como sujeitos desta narrativa (Perrot, 2017).

A coletânea apresentada pelo livro é um convite para pesquisadoras e profissionais de diversas áreas de conhecimento refletirem sobre as emoçóes e as condições de trabalho no cuidado. Enfermeiras e/ ou técnicas, empregadas domésticas e cuidadoras de idosos constroem, no e pelo trabalho, as emoçóes para lidar com as limitaçóes corporais com o outro, bem como suas próprias limitaçóes em uma atividade que exige disposição física e emocional, socialmente desvalorizada e precarizada. $\mathrm{O}$ conhecimento sobre o cuidado pode oferecer uma nova epistemologia sobre a realidade social, não só questionando modelos universais e generalistas, mas trazendo à luz os saberes que foram ocultados sobre o contexto social e os conhecimentos e experiências das pessoas que cuidam (Paperman, 2013). Historicamente, o trabalho de cuidado ficou delegado às mulheres, logo é evidente uma feminização nesta atividade, especialmente entre mulheres pobres, migrantes e que não se destacam no mercado de trabalho capitalista. 
Ademais, a obra contribui para expor e expandir as análises latino-americanas sobre o cuidado enquanto trabalho, dando voz às mulheres e proporcionando pistas sobre como elas constroem seus saberes nas contradiçốes da sociedade capitalista que as explora. Nesse sentido, concordamos com Federici (2019), ao problematizar o trabalho reprodutivo como aquele que alicerça o capitalismo e, portanto, contribui para a exploração das mulheres, ainda em dias atuais.

\section{BIBLIOGRAFLA}

ANDRADE, Cristiane Batista (2015), O trabalho de cuidar e educar: gênero, saber e poder, Curitiba, Appris.

FEDERICI, Sílvia. (2019), O ponto zero da Revolução: trabalho doméstico, reprodução e luta feminista. Tradução de Coletivo Sycorax, São Paulo, Elefante.
GILLIGAN, Carol. (1982), In a different voice: psychological theory and women development, Massachussettss, Harvard University Press.

KERGOAT, Danièle. (2016), "O cuidado e a imbricação das relaçôes sociais”, in H. S. Hirata \& N.A. Guimarães (org.), Gênero e trabalho no Brasil e na França: perspectivas interseccionais, São Paulo, Boitempo.

KLUCZYŃSKA, Urszula. (2017), "Motives for Choosing and Resigning from Nursing by Men and the Definition of Masculinity: a qualitative study". Journal of Advanced Nursing, 73 (6): 1366-76.

PAHO. Pan American Health Organization. (2011), Migración de Enfermeras en América Latina área de América del Sur. Washington, Serie Recursos Humanos para la Salud n ${ }^{\circ} 60$.

PAPERMAN, Patricia. (2013), Care et sentiments, Paris, PUF.

PERROT, Michèle. (2017), Os excluidos da História: operários, mulheres e prisioneiros, São Paulo, Paz e Terra.

SOARES, Ângelo. (2012), "As emoçôes do care", in H.S. Hirata \& N.A. Guimaraes (org), Cuidado e cuidadoras: várias faces do trabalho do care, São Paulo, Atlas. 